\title{
Time-Resolved Spectroscopic Investigation of Charge Trapping in Carbon Nitrides Photocatalysts for Hydrogen Generation
}

\author{
Robert Godin, ${ }^{\dagger}$ Yiou Wang, ${ }^{\ddagger}$ Martijn A. Zwijnenburg, ${ }^{\S}$ Junwang Tang, ${ }^{\ddagger}$ and James R. Durrant ${ }^{* \dagger}$ \\ ${ }^{\dagger}$ Department of Chemistry and Centre for Plastic Electronics, Imperial College London, South Kensington Campus, London SW7 \\ 2AZ, U.K. \\ ${ }^{\S}$ Department of Chemistry, University College London, 20 Gordon Street, London WC1H 0AJ, U.K. \\ ${ }^{\ddagger}$ Group of Solar Energy \& Advanced Materials, Department of Chemical Engineering, University College London, Torrington Place, \\ London WC1E 7JE, U.K.
}

\section{Supporting Information}

ABSTRACT: Carbon nitride $\left(\mathrm{g}-\mathrm{C}_{3} \mathrm{~N}_{4}\right)$ as a benchmark polymer photocatalyst is attracting significant research interest because of its visible light photocatalytic performance combined with good stability and facile synthesis. However, little is known about the fundamental photophysical processes of $\mathrm{g}-\mathrm{C}_{3} \mathrm{~N}_{4}$, which are key to explain and promote photoactivity. Using time-resolved absorption and photoluminescence spectroscopies, we have investigated the photophysics of a series of carbon nitrides on time scales ranging from femtoseconds to seconds. Free charge carriers form within a 200 fs excitation pulse, trap on the picosecond time scale with trap states in a range of energies, and then recombine with power law decays that are indicative of charge trapping-detrapping processes. Delayed photoluminescence is assigned to thermal excitation of trapped carriers back up to the conduction/

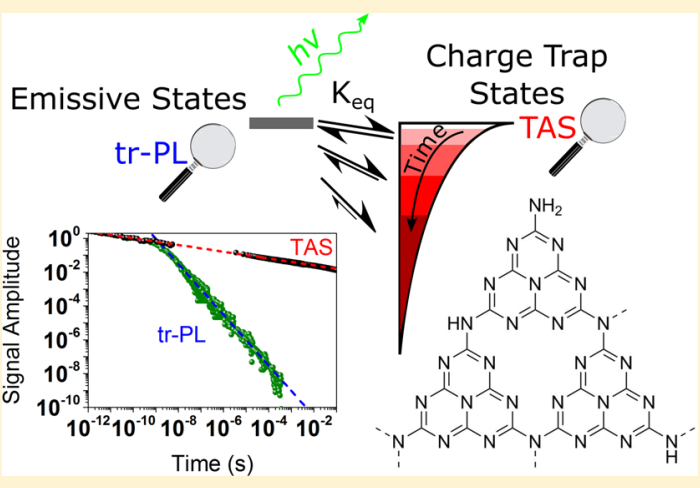
valence bands. We develop a simple, quantitative model for the charge carrier dynamics in these photocatalysts, which includes carrier relaxation into an exponential tail of trap states extending up to $1.5 \mathrm{eV}$ into the bandgap. This trapping reduces the efficiency of surface photocatalytic reactions. Deep trapped electrons observed on micro- to millisecond time scales are unable to reduce electron acceptors on the surface or in solution. Within a series of $g-\mathrm{C}_{3} \mathrm{~N}_{4}$, the yield of these unreactive trapped electrons correlates inversely with $\mathrm{H}_{2}$ evolution rates. We conclude by arguing that the photophysics of these carbon nitride materials show closer parallels with inorganic semiconductors than conjugated polymers, and that the key challenge to optimize photocatalytic activity of these materials is to prevent electron trapping into deep, and photocatalytically inactive, electron trap states.

\section{INTRODUCTION}

The development of new materials and devices for solar energy conversion is strongly dependent upon improving our understanding of photophysical properties that affect power conversion efficiency, thereby guiding improvements in materials synthesis, composition, and processing. With widespread adoption in mind, significant efforts are currently dedicated to develop systems based on earth abundant elements. Carbon nitrides (commonly referred to as $\mathrm{g}-\mathrm{C}_{3} \mathrm{~N}_{4}$ in the literature), composed of carbon and nitrogen, as well as usually hydrogen atoms, ${ }^{1}$ is so far the most promising target polymer material for photocatalytic solar energy conversion., Carbon nitride has a band and optical gap in the visible range, is easily prepared from inexpensive precursor materials ${ }^{4}$ and shows outstanding stability, especially considering its organic nature. ${ }^{5}$ Carbon nitrides have been used as (photo)catalysts in many systems, ${ }^{6}$ such as for water oxidation, 7,8 hydrogen production, ${ }^{7,9-11}$ overall water splitting, ${ }^{12-14}$ and water decontamination. ${ }^{15}$ Despite the high level of interest in the preparation and application of carbon nitrides, investigations of the dynamics of photogenerated charges are limited to date, and we are still lacking an understanding of the photophysical parameters that control photoactivity. While it is understood that modifying the preparation route will impact the photophysics and photochemistry of the product, ${ }^{2}$ the root cause of these changes remains unclear and direct links between charge carrier dynamics and photocatalytic efficiencies have yet to be drawn through systematic investigations. In particular, while several studies have indicated that charge carrier trapping resulting from chemical defects may be important in determining the photocatalytic activity of carbon nitride materials, ${ }^{9,16,17}$ quantitative analysis of the impact of such traps states, and their dependence upon material synthesis is lacking in the literature to date.

One of the most attractive routes for solar energy conversion is the production of $\mathrm{H}_{2}$ from water, ${ }^{11}$ ultimately to be performed without sacrificial reagents. Though the efficiency of $\mathrm{H}_{2}$ photoproduction by carbon nitride materials has been improved over the years, ${ }^{10,18,19}$ the limitations and the

Received: February 13, 2017

Published: March 20, 2017 
underlying photophysics of high performance $\mathrm{H}_{2}$ producing carbon nitride systems are not well understood. ${ }^{20}$ For example, it has not been conclusively established whether photoexcitation of carbon nitrides generates charge carriers, as in inorganic semiconductors, or generates bound excitons, as in conjugated polymers. This distinction is important to the design of carbon nitride systems as organic and inorganic semiconductors show different photophysics and limitations, and thus have different optimal device architecture. ${ }^{21}$ For these semiconductors, time-resolved optical spectroscopies [transient absorption (TAS) and time-resolved photoluminescence (tr$\mathrm{PL})$ ] have played an important role in developing our understanding of fundamental photophysical processes, ${ }^{22-29}$ and how charge trapping dictates photoactivity. ${ }^{30-34}$ tr-PL is often used to monitor trapping and its effects on the overall photophysics, ${ }^{28,29,35}$ although when the trapped states are nonemissive, TAS enables the direct observation of the dynamics of trapped carrier populations. ${ }^{36-38}$ Such tr-PL and TAS studies have been widely used for example to probe the dynamics of shallowly trapped carriers in organic donor/ acceptor blends and solar cells. ${ }^{34}$ However, our knowledge of the photophysics and charge trapping in carbon nitrides is still limited as there have been few photophysical studies performed using TAS. ${ }^{9,16,17,39-41}$

We set out herein to clarify the underlying excited state processes of a series of carbon nitride materials which differ in the synthesis temperature and hydrogen evolution rates; this series includes the benchmark urea-derived highly polymerized carbon nitride with one of the highest $\mathrm{H}_{2}$ production efficiency reported to date. ${ }^{20}$ We study the charge carrier dynamics in these materials over time scales ranging from femtoseconds to seconds in relevant operating conditions. We observe much faster tr-PL decays compared to those measured by TAS, and employ these data to propose a simple, quantitative model built upon fast equilibrium between high-energy emissive states and an exponential energetic distribution of low-energy, charge trapped, nonemissive states. TAS measurements on the microsecond to second time scale suggest that the population of trapped electrons are nonthermalizd, presumably due to a significant density of deep traps. These deeply trapped charges are nonreactive toward electron scavengers, and thus are nonproductive for $\mathrm{H}_{2}$ evolution as evidenced by the inverse correlation between the concentration of trapped electrons and photoactivity for urea-derived carbon nitride prepared at different temperatures.

\section{RESULTS}

Steady-State Spectroscopy. We focused our investigation of carrier dynamics of photoexcited carbon nitride on material derived from urea as a precursor that is prepared at a high temperature of $600{ }^{\circ} \mathrm{C}$, denoted $\mathrm{g}_{-} \mathrm{C}_{3} \mathrm{~N}_{4}-600$. This material shows one of the highest $\mathrm{H}_{2}$ photoactivity reported to date for carbon nitrides, with a quantum efficiency of $26.5 \%$ measured at $400 \mathrm{~nm}$ under one bar pressure. ${ }^{20}$ The ground state absorption and emission spectra of this carbon nitride, and others prepared at lower temperatures $\left(\mathrm{g}-\mathrm{C}_{3} \mathrm{~N}_{4}-500\right.$ and g$\mathrm{C}_{3} \mathrm{~N}_{4}-550$, prepared at 500 and $550{ }^{\circ} \mathrm{C}$, respectively), are found in Figure 1. For reference, the rates of $\mathrm{H}_{2}$ generation for these materials are shown in Figure $1 \mathrm{~B}$, as previously reported. ${ }^{20}$

The diffuse-reflectance absorption profile of the carbon nitrides studied herein is consistent with the sharp onset of a semiconductor direct bandgap transition. Tauc plots (Figure $\mathrm{S} 1$ ) show intrinsic bandgaps near $2.9 \mathrm{eV}$, slightly increased for
A

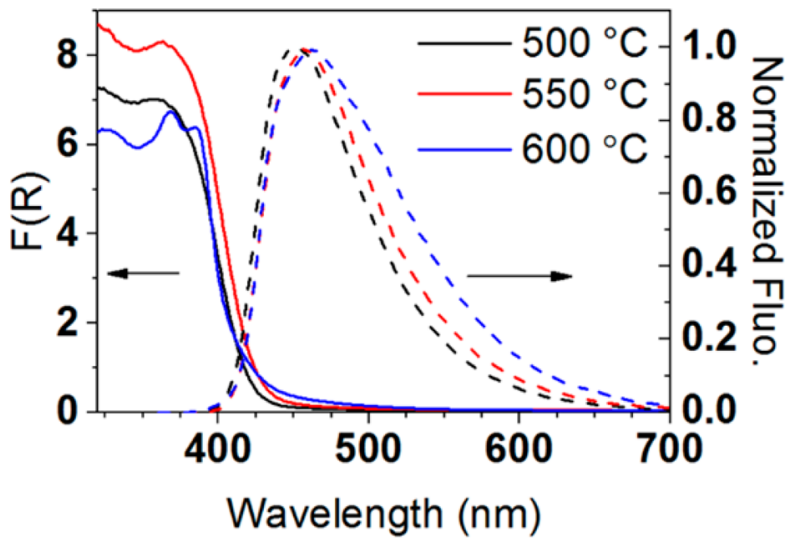

$\mathrm{B}$

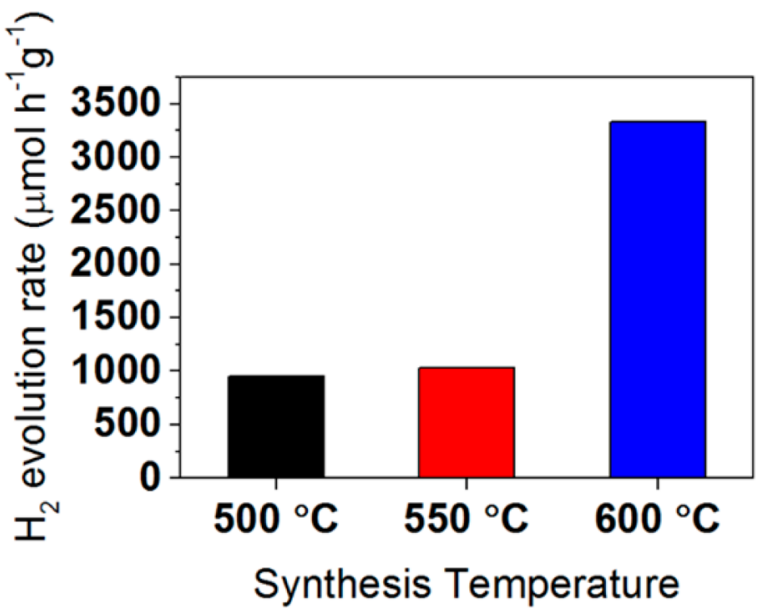

Figure 1. (A) Steady-state spectroscopy of urea derived g- $\mathrm{C}_{3} \mathrm{~N}_{4}$ prepared at different temperatures. UV-vis diffuse reflectance (solid lines) and emission spectra (dashed lines; $\lambda_{\mathrm{ex}}=355 \mathrm{~nm}$ ) were taken from powders in ambient air. (B) Hydrogen evolution rate of the carbon nitrides $(\lambda \geq 395 \mathrm{~nm}, 0.98 \mathrm{M}$ TEOA aqueous solution, one bar pressure, $300 \mathrm{~W}$ Xe lamp) as reported in ref 20 .

g- $\mathrm{C}_{3} \mathrm{~N}_{4}-600$, attributed to $\pi-\pi^{*}$ transitions. ${ }^{42,43}$ We also observe a tail of absorption below the bandgap in the 430$500 \mathrm{~nm}$ range, assigned to $\mathrm{n}-\pi^{*}$ transitions, ${ }^{42,44,45}$ which increases in amplitude for higher preparation temperatures. The increase in synthesis temperature has been linked to an increase of nonplanar sites that shift the bandgap to higher energies by limiting the extent of delocalization between heptazine rings and makes the $n-\pi^{*}$ transition more allowed by breaking the symmetry. ${ }^{42-46}$

The PL spectra of the carbon nitride powders were recorded under $355 \mathrm{~nm}$ excitation. Broad PL is emitted with a maximum near $450 \mathrm{~nm}$. The maxima shift from 440 to $460 \mathrm{~nm}$ and the peak broadens as the preparation temperature is increased. The PL spectra of carbon nitride has been explained in terms of multiple transitions involving $\pi$ conjugated states and $\mathrm{N}$ lone pairs. ${ }^{4,48}$ The high energy PL near $440 \mathrm{~nm}$, dominant in the more fluorescent samples prepared at lower temperatures, lies close to the bandgap, and may thus be attributed to emission from the band edges. ${ }^{45}$ Lower energy PL near $500 \mathrm{~nm}$, is then attributed to intra bandgap states, ${ }^{45}$ possibly involving tertiary $\mathrm{N}$ atoms. ${ }^{47}$ We fitted the PL emission to 2 Gaussian peaks to extract the high and low PL energies (Figure S2). Using this approach, we extract bands centered near 2.8 and $2.5 \mathrm{eV}$, which confirm that the high-energy PL lies close to the bandgap and 
provides an estimate that emissive intra bandgap states are roughly $0.3 \mathrm{eV}$ below the absorption band edges. Electroluminescence studies of carbon nitride have revealed PLinactive states that are more strongly red-shifted, peaking between 700 and $900 \mathrm{~nm}$, indicating that additional states are found $\sim 1-1.4 \mathrm{eV}$ below the band edges. ${ }^{49}$ In the case of $\mathrm{TiO}_{2}$, radiative recombination of trapped states have been linked to PL emission with large redshifts compared to the band edges. ${ }^{50}$ Therefore, we consider that PL emission of these carbon nitride materials only probes states lying near the band edges (shallow traps) rather than deeply trapped states involved in electroluminescence. The normalized UV-vis and PL spectra cross at $415 \mathrm{~nm}$ for $\mathrm{g}-\mathrm{C}_{3} \mathrm{~N}_{4}-600$, giving an adiabatic excitation energy of $2.99 \mathrm{eV}$, and we thus consider this the highest amount of energy contained in the excited state.

Time-Resolved Photoluminescence. We turned to tr-PL to investigate the decay of the emissive states over roughly 7 orders of magnitude in both time and signal intensity. The results for g- $\mathrm{C}_{3} \mathrm{~N}_{4}-600$ are shown in Figure 2 . The decay is well

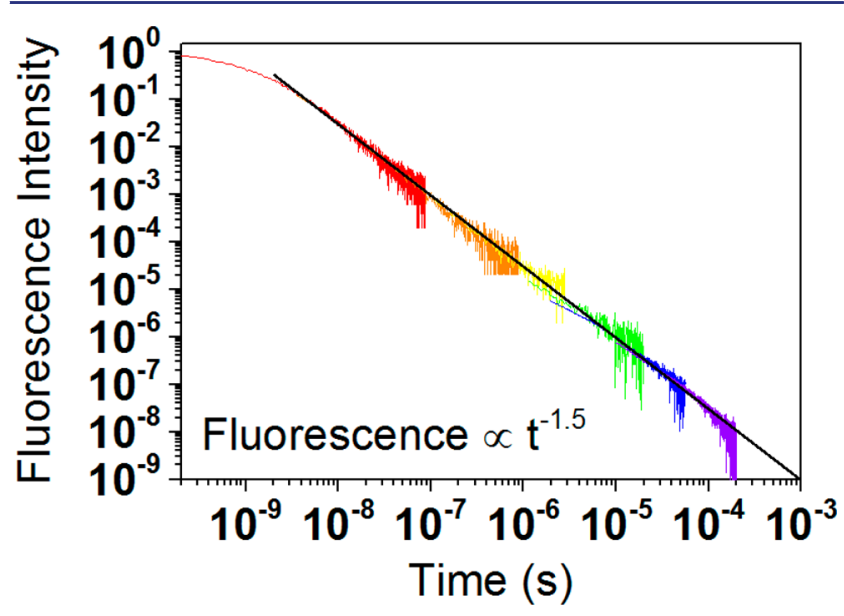

Figure 2. Fluorescence intensity decay of $\mathrm{g}^{-} \mathrm{C}_{3} \mathrm{~N}_{4}-600$ dispersion in $\mathrm{H}_{2} \mathrm{O}(2 \mathrm{mg} / \mathrm{mL}$ ) over ps-ms time scales. Data from TCSPC (red, orange and yellow lines; $\lambda_{\mathrm{ex}}=404 \mathrm{~nm}, \lambda_{\mathrm{mon}}=480 \mathrm{~nm}$ ) and the timeresolved intensity measured from a $\mathrm{Si}$ photodiode (green, blue and purple lines; $\lambda_{\mathrm{ex}}=355 \mathrm{~nm}, \lambda_{\mathrm{mon}}=550 \mathrm{~nm}$ ) are normalized to overlap in adjacent traces. The slope of the black line was set to -1.5 .

represented over all time scales by a power law of the form $I \propto$ $t^{-\beta}$, as evidenced by the linear decay on a $\log -\log$ plot. To cover such a wide range of time scales, we combined data from time-correlated single photon counting (TCSPC) measurements $(\mathrm{ps}-\mu \mathrm{s})$ and the temporal response of a Si photodiode $(\mu \mathrm{s}-\mathrm{ms})$. The results are consistent with previously reported observations over more limited time-ranges. ${ }^{39}$ No dependence on the slope of the decays with excitation fluence was observed and the power law exponent, $\beta$, of the PL decay was determined to be 1.5. We also recorded the time-resolved emission spectra (TRES) for different delay times (Figure S3), and observed a slight redshift in the emission maxima from 440 to $460 \mathrm{~nm}$ over the first $100 \mathrm{~ns}$. The TRES is comparable to the steady-state PL spectra, indicating a lack of significant relaxation and energy loss of the emissive states up to $475 \mathrm{~ns}$ (the longest time delay where we measured the TRES) and confirming that the energy of the emissive state lies near the band edges.

Transient Absorption Spectroscopy. In order to probe nonemissive states in photoexcited carbon nitride, we performed TAS studies over 12 orders of magnitude in time scale by combining fs-TAS (fs-ns) and $\mu \mathrm{s}$-TAS ( $\mu \mathrm{s}-\mathrm{s}$ ) measurements. The fs-TAS measurements revealed a bleaching signal between $500-600 \mathrm{~nm}$ and a positive absorption feature at wavelengths $>700 \mathrm{~nm}$ (Figure $3 \mathrm{~A}$ ). A comparable bleach has

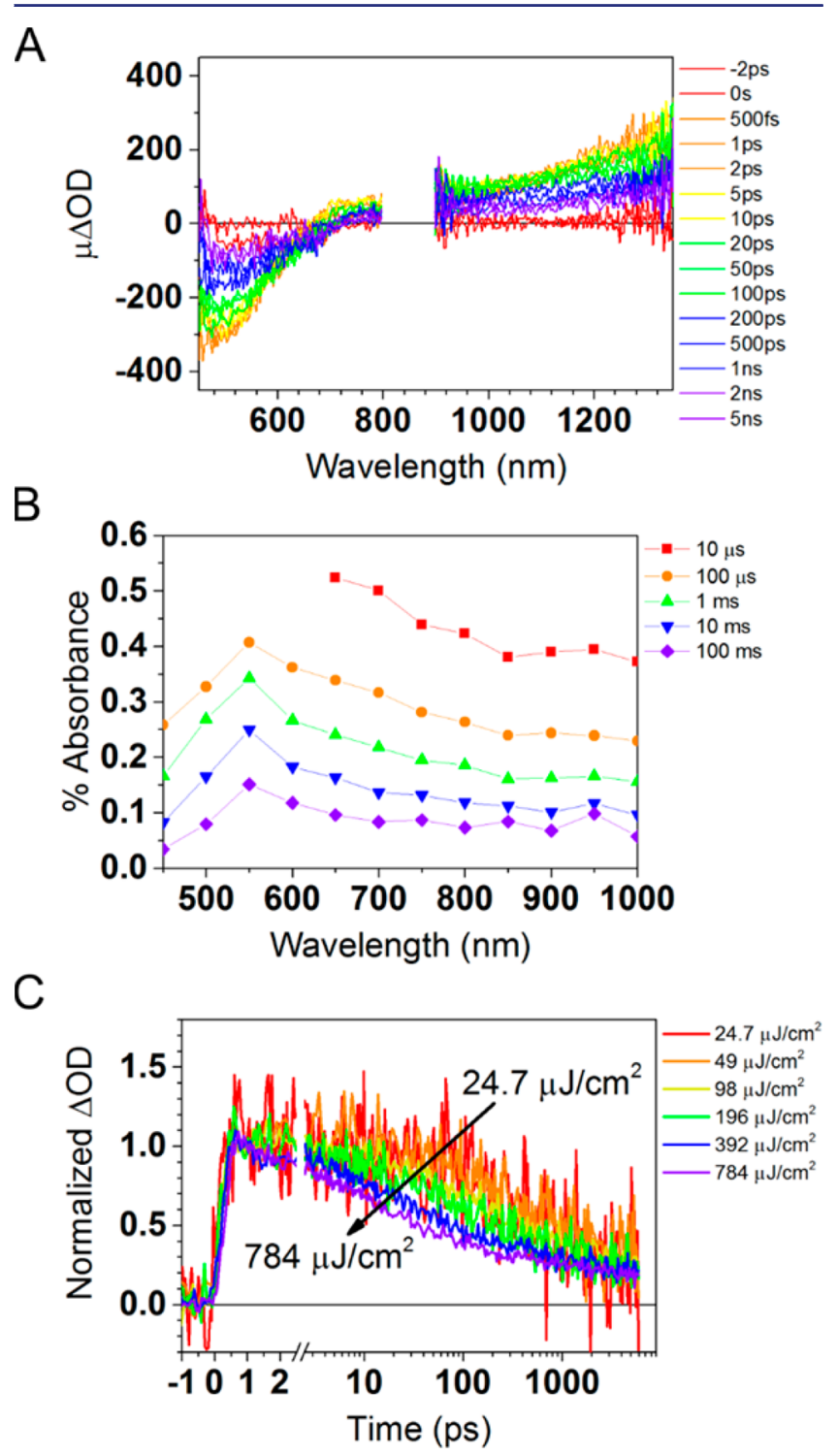

Figure 3. TAS spectra of $g-\mathrm{C}_{3} \mathrm{~N}_{4}-600$ aqueous dispersions at different delay times. (A) fs-TAS spectra of $0.2 \mathrm{mg} / \mathrm{mL}$ g- $\mathrm{C}_{3} \mathrm{~N}_{4}$ excited by 355 $\mathrm{nm}$ pulsed excitation $\left(48 \mu \mathrm{J} / \mathrm{cm}^{2}\right.$, width $\left.\sim 200 \mathrm{fs}\right)$. (B) $\mu \mathrm{s}$-TAS spectra of $2 \mathrm{mg} / \mathrm{mL}$ g- $\mathrm{C}_{3} \mathrm{~N}_{4}$ excited by $355 \mathrm{~nm}$ pulsed excitation $\left(360 \mu \mathrm{J} / \mathrm{cm}^{2}\right.$, width $\sim 7 \mathrm{~ns}$ ). (C) fs-TAS decay kinetics of $\mathrm{g}-\mathrm{C}_{3} \mathrm{~N}_{4}-600$ dispersions $(0.2 \mathrm{mg} / \mathrm{mL})$ in $\mathrm{H}_{2} \mathrm{O}$ probed at $505 \mathrm{~nm}$ for varying $355 \mathrm{~nm}$ excitation density.

been attributed to stimulated emission in previous fs-TAS investigations. $^{39}$ On slower time scales, $\mu$ s-TAS in diffuse reflectance geometry ${ }^{51}$ showed a broad positive feature in the visible and NIR regions, peaking at $550 \mathrm{~nm}$ (Figure 3B). Similar positive features have been observed in previous studies and has been assigned to both photogenerated holes ${ }^{41}$ or electrons, ${ }^{9,16,19}$ or also electron-hole pairs. ${ }^{16,40}$ The long-lived signal could be followed up to the second time scale, which makes it unlikely that we are monitoring bound electron-hole pairs that tend to recombine on sub $\mu$ s time scales. ${ }^{52,53}$ To elucidate the nature of this excited state, we performed 
measurements where holes or electrons were scavenged by chemical additives. In the presence of the hole scavenger TEOA, as used in the optimized photocatalytic system, fs-TAS experiments showed an initial increase in the photoinduced absorption feature above $700 \mathrm{~nm}$ (Figure S4). The initial amplitude of the transient absorption on microsecond time scales at $750 \mathrm{~nm}$ was also seen to increase in the presence of TEOA, and decrease in the presence electron scavengers (Pt on the carbon nitride surface or $\mathrm{Ag}^{+}$ions in solution; Figure S5). Additionally, the lifetime increased in TEOA compared to $\mathrm{H}_{2} \mathrm{O}$, consistent with reduced bimolecular charge recombination due to hole scavenging by the TEOA. Consequently, we attribute the positive absorption feature in the visible and NIR regions primarily to photogenerated electrons in the carbon nitride.

We next focus on the excitation fluence dependence of the fsTAS signal decay kinetics. We followed the decay of photoexcited carbon nitride near the bleach maxima at a probe wavelength of $505 \mathrm{~nm}$ for a 30-fold range of excitation densities (Figure 3C). At the highest fluence, the decay is clearly linear on a log-log plot, indicating a power law decay, as seen for the PL decays. However, the slope is significantly smaller, and a power law exponent $\alpha=0.2$ is extracted (Figure S6). All the decays at different excitation fluence converge to the same slope of -0.2 for times longer than 100 ps. Increasing the excitation density from 49 to $784 \mu \mathrm{J} / \mathrm{cm}^{2}$ resulted in a decrease of the half-life $\left(t_{50 \%}\right)$ of the excited state signal from 1 ns to 30 ps (Figure S6), consistent with nongeminate bimolecular recombination. We also extracted the $\alpha$ parameter from the changes in the decay dynamics following $t_{50 \%} \propto$ $n^{-1 / \alpha} .{ }^{54}$ Considering that the TAS signal is proportional to the concentration of photogenerated charges, we obtain $\alpha=0.6$ in this fashion, a value higher than obtained by analyzing the decay kinetics.

The kinetics observed on ultrafast time scales all decay to a small amplitude residual signal, as apparent in Figure 3, assigned to long-lived trapped charges. Consistent with this assignment, we note that transient spectra evolved on the ps-ns time scale (Figure S7) from a spectrum showing a progressively increasing signal at longer wavelengths, analogous to the Drude absorption of free electrons reported previously in metal oxides such as $\mathrm{TiO}_{2}$, ${ }^{55}$ to a flatter signal assigned to trapped charges. ${ }^{56}$ We thus conclude that initial charge trapping in this carbon nitride sample occurs within $<1 \mathrm{~ns}$, in kinetic competition with bimolecular recombination.

We also performed complementary measurements of these trapped charges on the slower microsecond to second time scale, using $\mu \mathrm{s}$-TAS. The decay of photogenerated electrons at $750 \mathrm{~nm}$ also showed power law behavior throughout the wide range of excitation fluences studied (Figure 4). Increasing the excitation fluence resulted in an increase in the TAS amplitude and the $\alpha$ exponent of the power law decay. At the lowest excitation fluence, $\alpha=0.11$ while it reaches values of 0.22 at the highest excitation fluences, similar to the fs-TAS decays. Notably, the signal amplitudes show large differences and do not overlap at long time scales (>100 ms). This behavior is similar to that seen in OPV blends with a high trap density where charges do not reach thermal equilibrium (Fermi-Dirac distribution). ${ }^{57}$ This is a good indication that carbon nitrides also possess high trap densities and charges may trap deeply, impeding thermalisation.

It is striking that the ultrafast data gives no indication of the presence of excitonic or bound charge transfer states, which would exhibit monomolecular, exponential decays. Rather, our

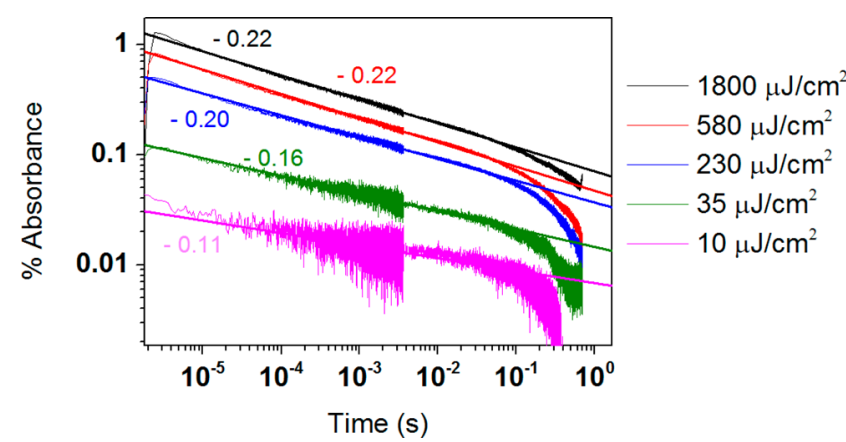

Figure 4. $\mu \mathrm{s}$-TAS decay kinetics of $\mathrm{g}-\mathrm{C}_{3} \mathrm{~N}_{4}-600$ dispersions $(2 \mathrm{mg} /$ $\mathrm{mL}$ ) in $\mathrm{H}_{2} \mathrm{O}$ probed at $750 \mathrm{~nm}$ for varying $355 \mathrm{~nm}$ excitation density. Best fit $\alpha$ parameters are indicated in the same color as the associated trace.

data indicate the direct photogeneration (with our instrument response of $\sim 200 \mathrm{fs}$ ) of dissociated charges that subsequently recombine primarily through a nongeminate pathway, as discussed above. Intrigued by this observation, we investigated the influence of the solvent surrounding the carbon nitride to establish if the charge separation was influenced by solvent polarity. We found the population of long-lived, trapped electrons to be only mildly sensitive to the solvent polarity, accompanied by small changes in the decay kinetics (Figure S8). While the results are consistent with high polarity solvents $\left(\mathrm{H}_{2} \mathrm{O}\right.$, ethylene glycol) promoting charge separation and/or impeding charge recombination, observed as higher initial amplitudes and longer lifetimes, the effect is relatively small, indicating that charge generation in the carbon nitride samples studied herein is inherent to the material rather than necessitating the involvement of the surrounding media.

We turn now to the investigation of electron transfer from the carbon nitride to the catalytically active sites of proton reduction, most commonly Pt deposited on the surface. ${ }^{7,14,20,58}$ On the one hand, TAS decays of carbon nitrides with and without photodeposited $\mathrm{Pt}$ revealed no significant changes in the charge carrier dynamics on the fs-ns time scale (Figure S9). On the other hand, on the $\mu$ s - s time scale we observed a $15 \%$ decrease in initial amplitude, but no changes in decay kinetics, when Pt was present (Figure S10). A larger initial decrease in amplitude of about $25 \%$ was observed using $\mathrm{Ag}^{+}$as the electron scavenger (Figure S5), but the kinetics are still indistinguishable from neat water and further indicates that we do not observe electron extraction on the $\mu \mathrm{s}-\mathrm{s}$ time scale. Therefore, it seems likely that electron transfer from carbon nitride to $\mathrm{Pt}$ on its surface occurs on the ns time scale and competes with charge trapping in the carbon nitride, as summarized later. It follows that strategies enabling electron extraction on the subns time scale should be pursued to increase photoactivity.

We finally studied the impact of synthesis temperature has on the microsecond charge carrier dynamics to link our results with the structure and photoactivity of this carbon nitride series. ${ }^{20}$ Our $\mu$ s-TAS measurements showed an increase in the signal amplitude as the synthesis temperature was lowered (Figure 5), corresponding to an inverse correlation with $\mathrm{H}_{2}$ production efficiency. This further supports our conclusion that on long (microsecond) time scales, we are monitoring unreactive trapped electrons. This trend indicates that carbon nitrides synthesized at lower temperatures show greater deep electron trapping that limit the proportion of active charges for 


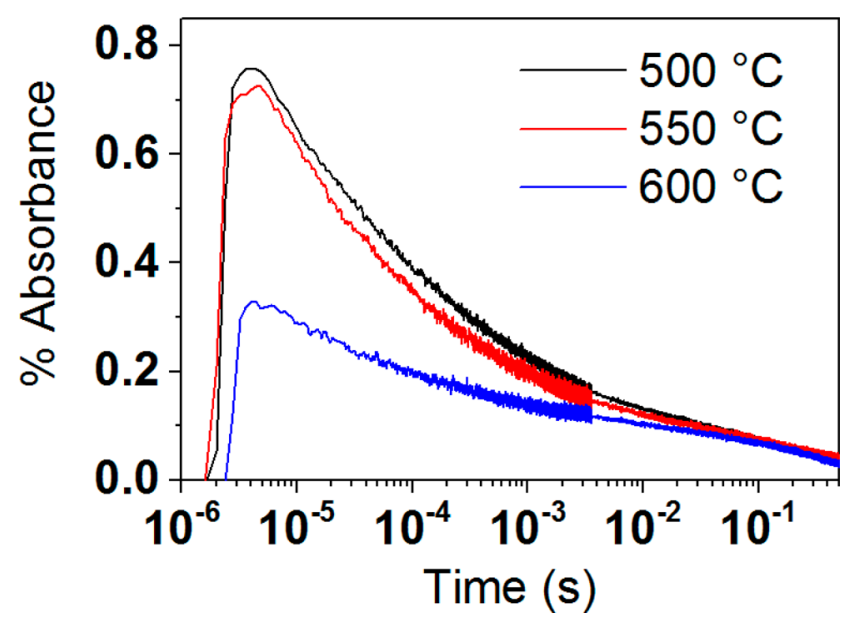

Figure 5. $\mu \mathrm{s}$-TAS decay kinetics of $\mathrm{g}-\mathrm{C}_{3} \mathrm{~N}_{4}$ dispersions $(2 \mathrm{mg} / \mathrm{mL}$ in aqueous $0.98 \mathrm{M}$ TEOA solution) synthesized at different temperatures monitored at $750 \mathrm{~nm}$ and excited by pulsed $355 \mathrm{~nm}$ excitation (180 $\left.\mu \mathrm{J} / \mathrm{cm}^{2}\right)$. The synthesis temperature was $500{ }^{\circ} \mathrm{C}\left(\mathrm{g}-\mathrm{C}_{3} \mathrm{~N}_{4}-500\right.$, black trace), $550{ }^{\circ} \mathrm{C}\left(\mathrm{g}-\mathrm{C}_{3} \mathrm{~N}_{4}-550\right.$, red trace) or $600{ }^{\circ} \mathrm{C}\left(\mathrm{g}-\mathrm{C}_{3} \mathrm{~N}_{4}-600\right.$, black trace).

$\mathrm{H}_{2}$ production. These results are in agreement with a recent investigation of carbon nitrides prepared from different precursors. ${ }^{16}$ We also observed similar $15 \%$ decrease of the initial amplitude when Pt was photodeposited on the different samples (Figure S11).

\section{DISCUSSION}

Simple Model Accounting for Distinct tr-PL and TAS Decays. We performed detailed investigations of charge carrier dynamics in carbon nitrides utilizing time-resolved spectroscopic techniques (TAS and tr-PL) that allowed for measurements spanning roughly 10 orders of magnitude in time and signal intensity. Figure 6 highlights the most striking result of this investigation: the faster decay of the PL signal compared to the TAS signal. Both decays are well represented by power laws

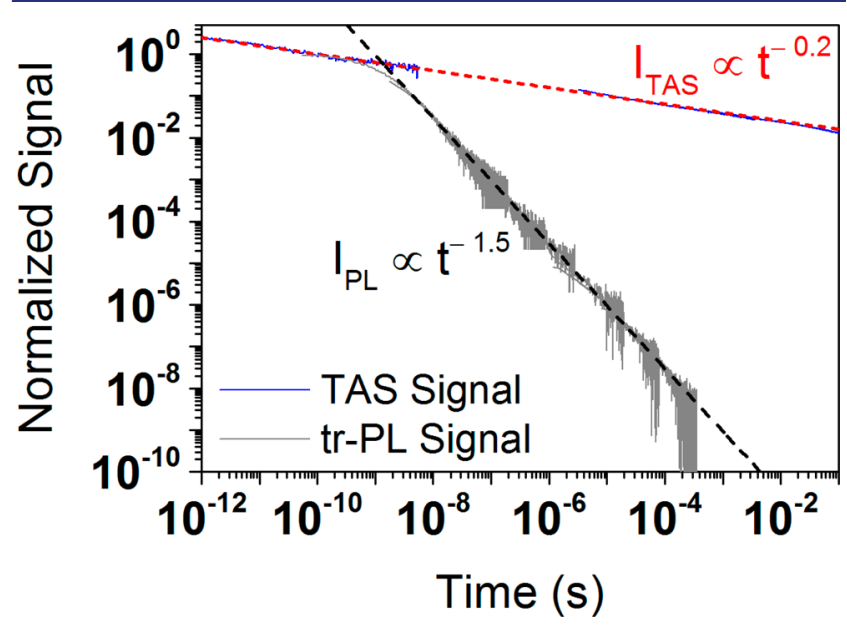

Figure 6. PL intensity (gray lines) or TAS amplitude (blue lines) decays of $\mathrm{g}_{-} \mathrm{C}_{3} \mathrm{~N}_{4}-600$ dispersion in $\mathrm{H}_{2} \mathrm{O}$ over fs $-\mathrm{s}$ time scales. Data from different time scales were scaled to emphasize the linearity of the decays. The PL (black dashes) and TAS (red dashes) signals are well represented by power law decays. The PL data is the same as in Figure 2. The TAS data shown is taken from the highest excitation fluences used in fs-TAS and $\mu$ s-TAS. of the form $I \propto t^{-\alpha}$ over all time scales. The power law exponent of the PL decay is 1.5. In contrast, much lower exponent values are found for the TAS decays, as low as 0.11 , and values near 0.2 were seen both on fs-ns and $\mu \mathrm{s}-\mathrm{s}$ time scales at high laser intensities.

Analysis of the PL spectra showed that the energy of the emissive states, either excitonic in nature or arising from recombination of free charges, ${ }^{38,44,59,60}$ lie near the band edges and does not arise from recombination of deeply trapped charges. On one hand, the tr-PL intensity $\left(I_{\mathrm{PL}}\right)$ exclusively monitors the population of high-energy emissive states $\left(n_{\mathrm{em}}\right)$. On the other hand, the TAS amplitude $\left(I_{\mathrm{TAS}}\right)$ monitors charge trapped states $\left(n_{\mathrm{CS}}\right)$ :

$$
\begin{aligned}
& I_{\mathrm{PL}}(t) \propto n_{\mathrm{em}}(t) \propto t^{-1.5} \\
& I_{\mathrm{TAS}}(t) \propto n_{\mathrm{CS}}(t) \propto t^{-\alpha}
\end{aligned}
$$

While we only observed a TAS signal consistent with photogenerated electrons, for generality we consider that the TAS monitors nonemissive trapped states where a significant amount of energy has been lost through electron trapping and potentially hole trapping. Consistent with the TAS decay power law exponents smaller than unity $(\alpha \sim 0.2)$, as frequently observed in studies of metal oxide semiconductors ${ }^{61-63}$ and organic photovoltaic blends, ${ }^{23,57}$ we suppose that an exponential tail of trap states below the band edges dictate recombination through trapping/detrapping of charges. ${ }^{64}$ This energetic trap distribution relates to $\alpha$ as

$$
n_{\text {trap }}(E) \propto \exp \left(-\frac{\alpha E}{k_{\mathrm{B}} T}\right)
$$

Here $n_{\text {trap }}(E)$ is the density of available trap states at energy $E$, $k_{\mathrm{B}}$ is Boltzmann's constant, and $T$ is temperature.

To explain the significant differences in decay dynamics of trPL and TAS signals, in light of the indications that significant charge trapping occurs in carbon nitride, we propose a simple trapping model schematically depicted in Figure 7, similar to

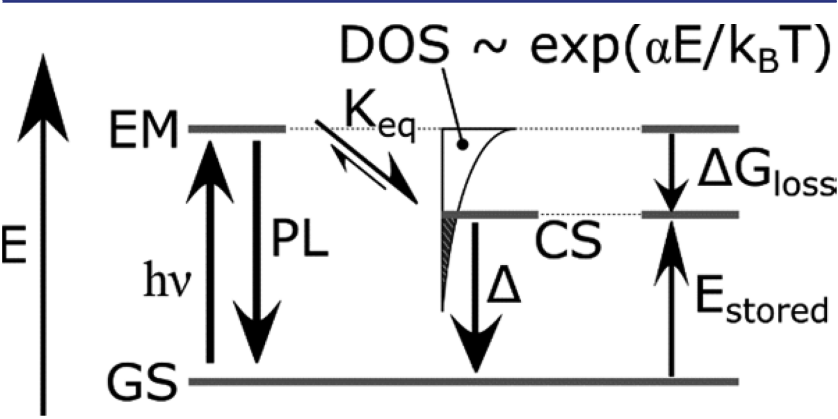

Figure 7. Schematic representation of proposed charge trapping model. GS stands for ground state, EM for emissive, CS for trapped charge separated, and DOS for density of states. Relaxation from EM to GS is presumed to be emissive, while the transition from CS to GS releases heat and is nonemissive. The highest occupied CS state determines the trapping energy loss, $\Delta G_{\text {loss }}$.

that developed in the case of an inorganic semiconductor. ${ }^{38} \mathrm{We}$ note this model has some parallels with models of thermal activated delayed luminescence (TADF) of interest for applications in organic light emitting diodes, ${ }^{65}$ with the distinction that the long-lived states from which the emissive states are thermally generated are not triplet states, as employed 
in TADF, but rather trapped charge separated states. We assume that the emissive (EM) and trapped charge separated (CS) states are under fast thermal equilibrium, such that the population ratios may be calculated by a Boltzmann distribution:

$$
\frac{n_{\mathrm{EM}}}{n_{\mathrm{CS}}}=K_{\mathrm{eq}}=\exp \left(-\frac{\Delta G_{\text {loss }}}{k_{\mathrm{B}} T}\right)
$$

where $K_{\text {eq }}$ is the equilibrium constant, and $\Delta G_{\text {loss }}$ equals the excited state energy lost through trapping.

The excited state processes begin with photoexcitation of carbon nitrides to produce EM states that may recombine radiatively or trap energetically to form CS states, losing energy in the process $\left(\Delta G_{\text {loss }}\right)$. Charge recombination leads to a decrease in the population of CS, in turn increasing in the energetic barrier to reach EM states $\left(\Delta G_{\text {loss }}\right)$. The thermal equilibrium pushes further toward CS (lower $K_{\text {eq }}$ ), depopulating EM. Qualitatively, this results in a faster decay of EM when compared to CS states, in agreement with the faster decay of the PL vs TAS. Explicitly, if we assume that all CS states lower in energy than $E_{\mathrm{EM}}-\Delta G_{\text {loss }}$ are occupied, combining eqs $1-4$ leads us to write the temporal dependence of EM states in relation to $\alpha$ as

$$
n_{\mathrm{EM}} \propto t^{-(1+\propto)}
$$

The model quantitatively predicts that the EM state population decays with a power law exponent 1 unit greater than that of the CS state. In this case, taking $\alpha=0.2$ as the most representative value from TAS measurements, we would predict a tr-PL power law decay with an exponent of 1.2, indeed near the experimental value of 1.5. The discrepancy may be caused by factors not taken into account such as an active nonradiative recombination pathway from the high-energy emissive states, the Fermi distribution of charge trapped states, or a nonthermalizd distribution of occupied trap states as suggested by TAS measurements (see SI). Future refinements to the model would be able to address these points. Ultimately, we propose that a thermal equilibrium between emissive and trapped states account for the faster tr-PL vs TAS decays, and is likely involved in controlling photophysical properties of carbon nitrides.

We next performed a quantitative analysis of the free energy loss resulting from charge trapping in the framework of our model (see SI for details). The TAS data allows us to calculate the population of trap states and the maximal energy stored $\left(E_{\text {stored }}\right)$ per state over time (Figure $8 \mathrm{~A}$ ). We also show how the nominal charge transfer rate (determined from the product of the surviving carrier population and the relative charge transfer rate constant from Marcus theory, see "Calculation of charge transfer rate over time" in the SI for more details) decreases over time, highlighting the notion that charge transfer reactions become much slower over time as a result of both decreased population and decreased driving force. Figure $8 \mathrm{~B}$ shows the calculated $E_{\text {stored }}$ at different excitation fluences. For the lowest excitation fluence, $E_{\text {stored }} \sim 1.5 \mathrm{eV}$, corresponding to an energy loss of $\sim 1.5 \mathrm{eV}$ due to trapping. On this basis, we consider that a significant density of trap states are found at energies of $1 \mathrm{eV}$ or more below the band edges, consistent with the emission energy of carbon nitride seen by electroluminescence. ${ }^{49}$

Initial Charge Formation and Separation. Considering the experiments performed under varying excitation fluences, the observed acceleration of recombination rate for higher
A

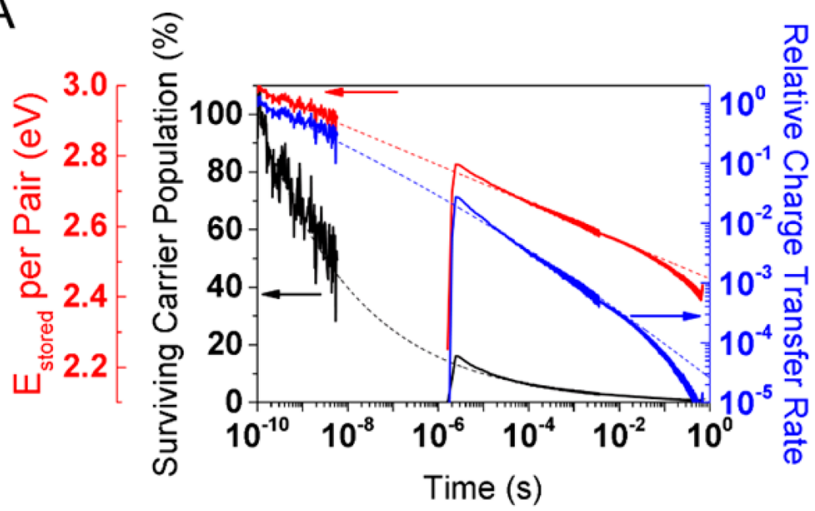

B

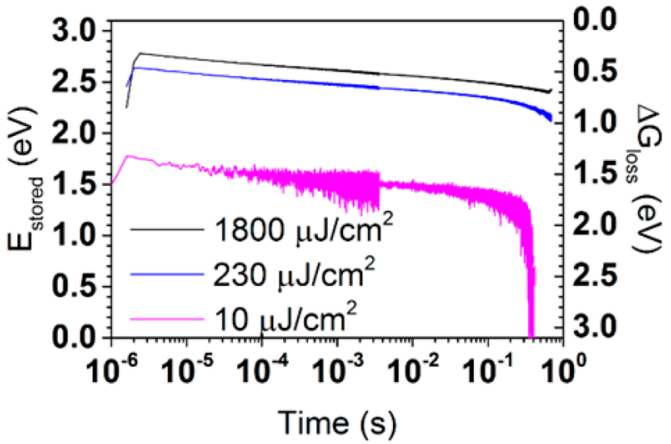

Figure 8. (A) Surviving carrier population, $E_{\text {stored }}$ and estimated relative charge transfer rate of $\mathrm{g}-\mathrm{C}_{3} \mathrm{~N}_{4}-600$ under high excitation fluence $\left(784 \mu \mathrm{J} / \mathrm{cm}^{2}<10 \mathrm{~ns}, 1800 \mu \mathrm{J} / \mathrm{cm}^{2}>1 \mu \mathrm{s}\right)$. The relative charge transfer rate was calculated as the product of the surviving carrier population and the relative charge transfer rate constant from Marcus theory as detailed in the SI. Dashed lines represent extrapolations based on the TAS signal power law decay with $\alpha=0.2$. (B) $E_{\text {stored }}$ as a results of charge trapping over time for varying excitation fluences $\left(\lambda_{\text {ex }}\right.$ $=355 \mathrm{~nm}$ ).

fluences are consistent with bimolecular recombination of charges, as seen in inorganic semiconductors. ${ }^{55,56,66,67}$ In addition, the fs-TAS experiments probing the NIR region indicate an ultrafast ( $<200 \mathrm{fs})$ charge separation process, as previously suggested, ${ }^{39,40}$ and is further typical of metal oxide semiconductors. ${ }^{56,68,69}$ In contrast, bound excitons are usually formed in neat conjugated polymer films, and effective charge separation is driven by blending with another component to form donor-acceptor heterojunctions. ${ }^{21,70,71}$

This brings the question as to what is causing charge separation in carbon nitrides as they are thought to have properties similar to conjugated polymers, notably a low dielectric coefficient $(\sim 5)^{72,73}$ and localized excited states. ${ }^{59,72}$ Our experiments performed in surrounding media with dielectric constants between 1 and 80 did not result in dramatic changes in the generation of charges. This suggests that charge separation predominately occurs within the carbon nitride material rather than at the interface with the solvent. The origin of this efficient charge generation is unclear; it is possible that some types of defects sites, possibly primary or secondary amines, cyanamides, and oxygen-bearing groups, could be involved in driving the charge separation process as well as charge trapping. ${ }^{74}$

Considerations for Photoactivity. Our model and analysis gives us important insight in the energetics of the trapped states. We estimate that a significant amount of deep traps are present and results in large energy losses of $1 \mathrm{eV}$ or 
more. This is also consistent with the results of Kuriki et al. that showed slower electron transfer kinetics from carbon nitride to $\mathrm{Ag}$ if considering electrons in deep traps, monitored in the visible and NIR region as in this study, compared to shallow traps, monitored in the mid-IR region. ${ }^{17}$ Furthermore, Walsh et al. linked the observed TAS signal on the $\mu \mathrm{s}-\mathrm{ms}$ time scale to trapped charges, and showed that their density is inversely proportional to the photoactivity of samples. ${ }^{16}$ As such, carbon nitride can accumulate deeply trapped long-lived electrons (lifetime $1 \mu \mathrm{s}$ or longer) that are unreactive toward photocatalytic production of $\mathrm{H}_{2}$. A large energy loss as a result of trapping would certainly lead to a reduction in driving force for charge transfer reactions, and is perhaps the reason why electrons are unable to transfer to $\mathrm{Pt}$ and reduce protons on $\mu \mathrm{s}$ time scales or longer (see Figure 9). According to the

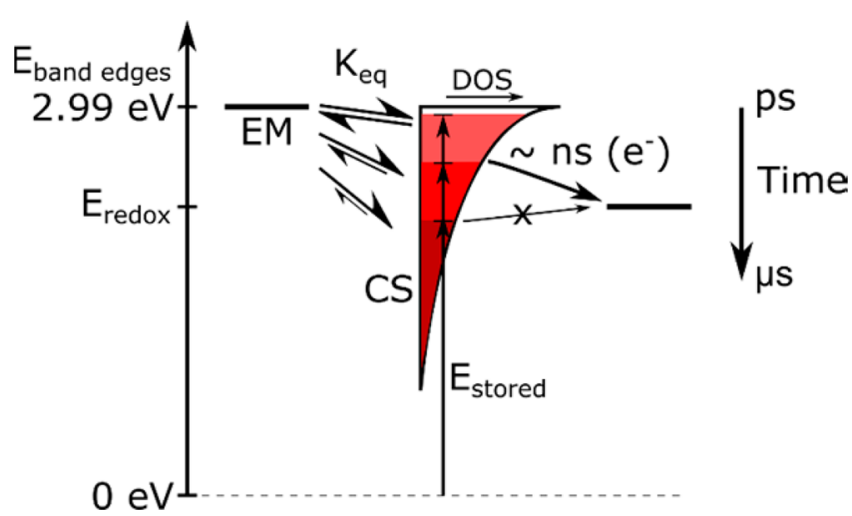

Figure 9. Schematic representation of the influence of trapping on charge transfer reactions, over time scales ranging from picoseconds to microseconds. EM and CS stands for the emissive and charge separated states, respectively, and $K_{\mathrm{eq}}$ is the equilibrium constant between these states. The red shaded area represents filled CS states, and evolves in time with darkening shade. Charge transfer reaction for electrons presumably occur on the ns time scale.

conduction band position of carbon nitride $(-1.3 \mathrm{~V}$ vs $\mathrm{NHE})^{75}$ and the proton reduction potential of $-590 \mathrm{mV}$ vs $\mathrm{NHE}$ at $\mathrm{pH}=10$, a loss of $600-700 \mathrm{meV}$ in energy stored would result in complete loss of driving force for proton reduction, values well within the observed energy losses. However, considering energy losses up to $2.1 \mathrm{eV}$, there should remain sufficient thermodynamic driving force for electron transfer to $\mathrm{Ag}^{+}\left(E_{\mathrm{Ag} / \mathrm{Ag}+}=0.799 \mathrm{~V}\right.$ vs $\left.\mathrm{NHE}\right)$, yet we observe incomplete quenching of the TAS signal in its presence. Although this may be caused by weak interactions between $\mathrm{Ag}^{+}$ and carbon nitride, together with the limited electron transfer to deposited Pt these results suggest that spatial confinement and localization of deeply trapped electrons limit their ability to participate in charge transfer reactions, as previously suggested. $^{20}$

$\mu$ s-TAS measurements on our series of carbon nitrides prepared at temperatures between 500 and $600{ }^{\circ} \mathrm{C}$ revealed an inverse relationship between the population of trapped electrons and the photoactivity. For example, g- $\mathrm{C}_{3} \mathrm{~N}_{4}-500$ shows a 3.5-fold reduced activity and 2.4-fold increased population of trapped electrons at $5 \mu \mathrm{s}$ compared to $\mathrm{g}-\mathrm{C}_{3} \mathrm{~N}_{4}$ 600. We also observed the same reduction in amplitude upon Pt photodeposition for the different samples. This suggests that competition between electron transfer to $\mathrm{Pt}$ and charge trapping is unaffected by the synthesis temperature. Assuming an equal number of absorbed photons for all samples, the increase in trapped electron yield for material prepared at lower temperature indicates that more energy is wasted through relaxation into deep trap sites, leading to lower photoactivity. Lowering the preparation temperature has been linked to a decrease in polymerization, which may suggest that primary or secondary amine sites may play a role in the formation of unreactive deeply trapped electrons. ${ }^{20}$ In situ EPR spectroscopy has suggested that photogenerated electrons are surfacetrapped with preferentially carbon character ${ }^{76}$ and show a distribution of delocalization over heptazine repeat units. ${ }^{77}$

We now consider the origin of the trap states we observe in our carbon nitride samples from a theoretical perspective. Following previous work, ${ }^{78}$ DFT and TD-DFT (TimeDependent DFT) calculations were performed on a simple structural model of carbon nitride comprising a hexamer of heptazine rings, without (H6L-H) and with (H6L-H-urea) the inclusion of a pendant urea defect. Full calculation details are given in the Supporting Information. Pendant urea chemical defects have been recently proposed to be present in carbon nitride materials synthesized using urea as precursor. ${ }^{79}$ The resulting HOMO and LUMO orbitals are shown in Figure 10.
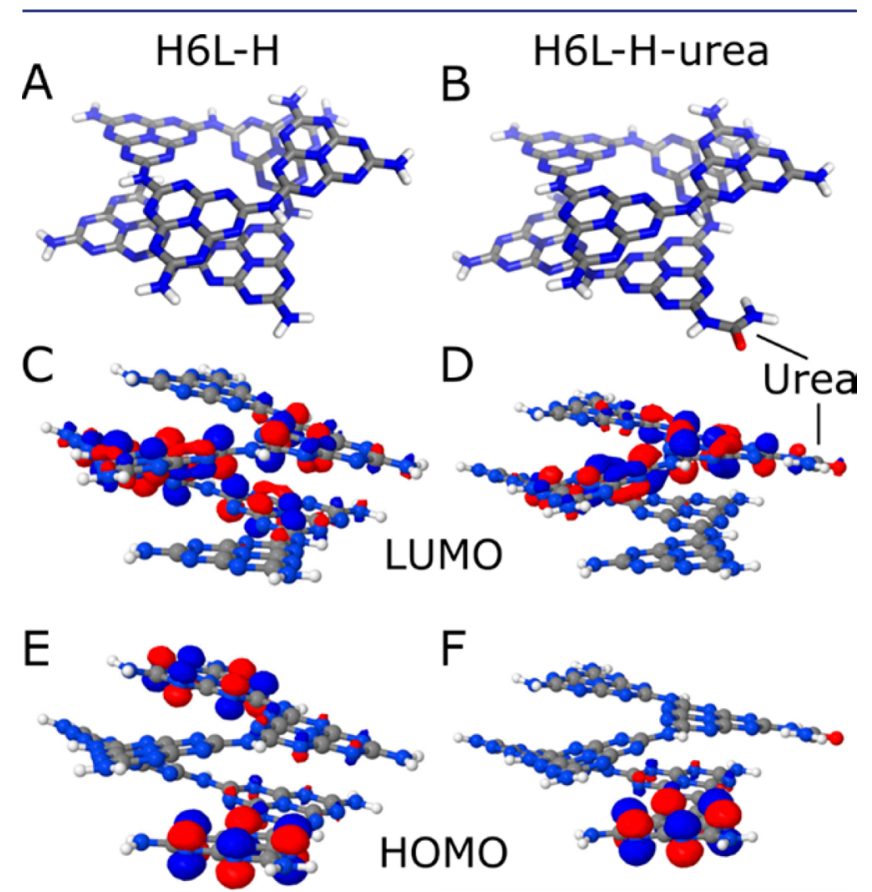

Figure 10. (Top) B3LYP optimized structures of carbon nitride oligomers for "defect-free" (H6L-H, panel A) and with urea defect (H6L-H-urea, panel B) cases. Carbon atoms are shown in gray, nitrogen in blue, hydrogen in white, and oxygen in red. (Middle and bottom) Comparison of the B3LYP lowest unoccupied (LUMO, panels $\mathrm{C}$ and $\mathrm{D}$ ) and highest occupied molecular orbital (HOMO, panels $\mathrm{E}$ and F) of the H6L-H and H6L-H-urea oligomers illustrating that the presence of a urea defect perturbs the frontier orbitals.

Inclusion of the urea defect results in partial shift of the localization of the HOMO orbital away from, and LUMO orbital toward, the pendant urea group, linked with the stabilization of photogenerated electron and holes by ca. 150 $\mathrm{meV}$ each. Qualitatively similar results were obtained with hydroxyl defects, but with smaller trapping energies. While these model system calculations lack the breadth and complexity required for quantitative comparison with the trapping energies determined from our experimental data 
(neglecting for example structural and energetic disorder), they confirm that typical chemical defects present in carbon nitride materials can indeed stabilize charge-separated states relative to emissive state by $100 \mathrm{~s}$ of $\mathrm{meV}$. Such states could therefore both provide energetic offsets to facilitate charge separation and retard recombination. Identifying the precise chemical nature of these trap sites, and clarifying their involvement in charge transfer steps, would enable engineering of intra band states and excited state dynamics through rational design of synthetic or modification procedures. ${ }^{80,81}$

In the context of water splitting, the high concentration of long-lived trapped electrons is expected to be detrimental to the hole accumulation needed to facilitate water oxidation ${ }^{82}$ through increased bimolecular electron-hole charge recombination. Developing procedures that produce carbon nitrides with lower trap density seems like a promising avenue for improvement. We do note that long-lived electrons in carbon nitride are not necessarily unreactive. Through postsynthetic modification of carbon nitride to install cyanimide groups, ${ }^{74}$ we have previously observed electron extraction and $\mathrm{H}_{2}$ production $30 \mathrm{~min}$ after light exposure and electron accumulation on the carbon nitride, 9 and "dark" photocatalysis can even occur over a period of hours. ${ }^{77}$ It is thus possible to control the reactivity of trapped electrons, possibly by influencing the density of trap states, through engineering of the terminal groups and is a promising route to further improve the efficiency of $\mathrm{H}_{2}$ photoproduction.

\section{CONCLUSIONS}

We have performed tr-PL and TAS investigations over 10 orders of magnitude in time and signal intensity of a high performance carbon nitride dispersion to elucidate fundamental excited state processes that dictate photoactivity. We developed a simple model to explain the much faster decay of the tr-PL signal compared to the TAS signal by taking into account the presence of nonradiative charge trap states in thermal equilibrium with emissive states lying near the band edges. Initial charge separation in carbon nitride seems to occur on subps time scales, with minimal involvement of the solvent interface. Overall, the photophysics of carbon nitride materials show strong parallels to metal oxide semiconductors, rather than the structurally more similar conjugated polymers used in photovoltaic applications.

We observe that photogenerated electrons can have lifetimes in the $\mu \mathrm{s}-\mathrm{s}$ time scale, but that these long-lived charges are not transferred to electron acceptors or catalytic sites and are unable to participate in $\mathrm{H}_{2}$ production. A high concentration of trapped unreactive electrons would severely impede accumulation of holes necessary for multihole water oxidation. Furthermore, the energetic distribution of the filled trap states are indicative of nonthermalized behavior, which may play a role in controlling the photoactivity. Increased polymerization and reduced hydrogen content in the carbon nitride, through higher preparation temperature, is shown to reduce the proportion of accumulated unreactive electrons, presumably key to the increased photoactivity. A key challenge is therefore to identify and tune ${ }^{74,79}$ the chemical nature of the sites involved in charge separation and trapping in order to increase the proportion of reactive photogenerated charges. Further insights into the trapping of electrons (and holes), both in terms of thermodynamic and localization considerations, and related structure-activity relationships will benefit the design of carbon nitride materials with high $\mathrm{H}_{2}$ evolution rates, and will also bring us a step closer to carbon nitride-driven efficient overall water splitting.

\section{ASSOCIATED CONTENT}

\section{Supporting Information}

The Supporting Information is available free of charge on the ACS Publications website at DOI: 10.1021/jacs.7b01547.

Experimental and computational details, steady-state optical spectra, expanded TAS results, calculation of $\Delta G_{\text {loss }}$ for different $\alpha$ values and comparison to expected trends (PDF)

\section{AUTHOR INFORMATION}

\section{Corresponding Author}

*j.durrant@imperial.ac.uk

ORCID

Robert Godin: 0000-0001-7945-8548

Martijn A. Zwijnenburg: 0000-0001-5291-2130

\section{Notes}

The authors declare no competing financial interest.

Data underlying this article will be made available on the Zenodo repository at DOI: 10.5281 /zenodo.400776.

\section{ACKNOWLEDGMENTS}

This work is supported by the ERC AdG Intersolar (291482). R.G. is grateful to FRQNT for a postdoctoral award. Y.W. and J.T. acknowledge financial support from EPSRC (EP/ N009533/1) and Royal Society Newton Advanced Fellowship grant (NA150418). Y.W. would also like to thank the CSC for Ph.D. funding. M.A.Z. acknowledges the EPSRC for funding (grant EP/I004424/1).

\section{REFERENCES}

(1) Lotsch, B. V.; Döblinger, M.; Sehnert, J.; Seyfarth, L.; Senker, J.; Oeckler, O.; Schnick, W. Chem. - Eur. J. 2007, 13, 4969.

(2) Ong, W.-J.; Tan, L.-L.; Ng, Y. H.; Yong, S.-T.; Chai, S.-P. Chem. Rev. 2016, 116, 7159.

(3) Vyas, V. S.; Lau, V. W.-h.; Lotsch, B. V. Chem. Mater. 2016, 28, 5191.

(4) Zheng, Y.; Liu, J.; Liang, J.; Jaroniec, M.; Qiao, S. Z. Energy Environ. Sci. 2012, 5, 6717.

(5) Wang, Y.; Wang, X.; Antonietti, M. Angew. Chem., Int. Ed. 2012, 51,68 .

(6) Liu, J.; Wang, H.; Antonietti, M. Chem. Soc. Rev. 2016, 45, 2308.

(7) Wang, X.; Maeda, K.; Thomas, A.; Takanabe, K.; Xin, G.; Carlsson, J. M.; Domen, K.; Antonietti, M. Nat. Mater. 2009, 8, 76.

(8) Zhang, J.; Sun, J.; Maeda, K.; Domen, K.; Liu, P.; Antonietti, M.; Fu, X.; Wang, X. Energy Environ. Sci. 2011, 4, 675.

(9) Kasap, H.; Caputo, C. A.; Martindale, B. C.; Godin, R.; Lau, V. W.; Lotsch, B. V.; Durrant, J. R.; Reisner, E. J. Am. Chem. Soc. 2016, 138,9183

(10) Cao, S.; Low, J.; Yu, J.; Jaroniec, M. Adv. Mater. 2015, 27, 2150.

(11) Cao, S.; Yu, J. J. Phys. Chem. Lett. 2014, 5, 2101.

(12) Lee, R.-L.; Tran, P. D.; Pramana, S. S.; Chiam, S. Y.; Ren, Y.; Meng, S.; Wong, L. H.; Barber, J. Catal. Sci. Technol. 2013, 3, 1694.

(13) Liu, J.; Liu, Y.; Liu, N.; Han, Y.; Zhang, X.; Huang, H.; Lifshitz, Y.; Lee, S.-T.; Zhong, J.; Kang, Z. Science 2015, 347, 970.

(14) Zhang, G.; Lan, Z.-A.; Lin, L.; Lin, S.; Wang, X. Chem. Sci. 2016, 7, 3062 .

(15) Xiao, J.; Xie, Y.; Nawaz, F.; Jin, S.; Duan, F.; Li, M.; Cao, H. Appl. Catal., B 2016, 181, 420.

(16) Walsh, J. J.; Jiang, C.; Tang, J.; Cowan, A. J. Phys. Chem. Chem. Phys. 2016, 18, 24825. 
(17) Kuriki, R.; Matsunaga, H.; Nakashima, T.; Wada, K.; Yamakata, A.; Ishitani, O.; Maeda, K. J. Am. Chem. Soc. 2016, 138, 5159.

(18) Liu, G.; Wang, T.; Zhang, H.; Meng, X.; Hao, D.; Chang, K.; Li, P.; Kako, T.; Ye, J. Angew. Chem., Int. Ed. 2015, 54, 13561.

(19) Lin, L.; Ou, H.; Zhang, Y.; Wang, X. ACS Catal. 2016, 6, 3921.

(20) Martin, D. J.; Qiu, K.; Shevlin, S. A.; Handoko, A. D.; Chen, X.;

Guo, Z.; Tang, J. Angew. Chem., Int. Ed. 2014, 53, 9240.

(21) Gregg, B. A. J. Phys. Chem. B 2003, 107, 4688.

(22) Clarke, T. M.; Durrant, J. R. Chem. Rev. 2010, 110, 6736.

(23) Ohkita, H.; Ito, S. Polymer 2011, 52, 4397.

(24) Cowan, A. J.; Durrant, J. R. Chem. Soc. Rev. 2013, 42, 2281.

(25) Baxter, J. B.; Richter, C.; Schmuttenmaer, C. A. Annu. Rev. Phys. Chem. 2014, 65, 423.

(26) Choi, W.; Termin, A.; Hoffmann, M. R. J. Phys. Chem. 1994, 98, 13669.

(27) Christians, J. A.; Manser, J. S.; Kamat, P. V. J. Phys. Chem. Lett. 2015, 6, 2086.

(28) Wu, K.; Zhu, H.; Lian, T. Acc. Chem. Res. 2015, 48, 851.

(29) Burda, C.; Link, S.; Mohamed, M.; El-Sayed, M. J. Phys. Chem. B 2001, 105, 12286

(30) Yamanaka, K.-i.; Sato, S.; Iwaki, M.; Kajino, T.; Morikawa, T. J. Phys. Chem. C 2011, 115, 18348.

(31) Barnes, P. R. F.; Anderson, A. Y.; Durrant, J. R.; O’Regan, B. C. Phys. Chem. Chem. Phys. 2011, 13, 5798.

(32) Barroso, M.; Pendlebury, S. R.; Cowan, A. J.; Durrant, J. R. Chem. Sci. 2013, 4, 2724.

(33) Thompson, T. L.; Yates, J. T. Chem. Rev. 2006, 106, 4428.

(34) Melianas, A.; Etzold, F.; Savenije, T. J.; Laquai, F.; Inganäs, O.; Kemerink, M. Nat. Commun. 2015, 6, 8778.

(35) Underwood, D. F.; Kippeny, T.; Rosenthal, S. J. J. Phys. Chem. B 2001, 105, 436.

(36) Wojdyla, M.; Gallagher, S. A.; Moloney, M. P.; Gun'ko, Y. K.; Kelly, J. M.; Magno, L. M.; Quinn, S. J.; Clark, I. P.; Greetham, G. M.; Towrie, M. J. Phys. Chem. C 2012, 116, 16226.

(37) Kim, W. D.; Kim, J.-H.; Lee, S.; Lee, S.; Woo, J. Y.; Lee, K.; Chae, W.-S.; Jeong, S.; Bae, W. K.; McGuire, J. A.; Moon, J. H.; Jeong, M. S.; Lee, D. C. Chem. Mater. 2016, 28, 962.

(38) Vietmeyer, F.; Frantsuzov, P. A.; Janko, B.; Kuno, M. Phys. Rev. B: Condens. Matter Mater. Phys. 2011, 83, 115319.

(39) Merschjann, C.; Tschierlei, S.; Tyborski, T.; Kailasam, K.; Orthmann, S.; Hollmann, D.; Schedel-Niedrig, T.; Thomas, A.; Lochbrunner, S. Adv. Mater. 2015, 27, 7993.

(40) Zhang, H.; Chen, Y.; Lu, R.; Li, R.; Yu, A. Phys. Chem. Chem. Phys. 2016, 18, 14904.

(41) Ye, C.; Li, J.-X.; Li, Z.-J.; Li, X.-B.; Fan, X.-B.; Zhang, L.-P.; Chen, B.; Tung, C.-H.; Wu, L.-Z. ACS Catal. 2015, 5, 6973.

(42) Jorge, A. B.; Martin, D. J.; Dhanoa, M. T. S.; Rahman, A. S.; Makwana, N.; Tang, J.; Sella, A.; Corà, F.; Firth, S.; Darr, J. A.; McMillan, P. F. J. Phys. Chem. C 2013, 117, 7178.

(43) Deifallah, M.; McMillan, P. F.; Corà, F. J. Phys. Chem. C 2008, $112,5447$.

(44) Zhang, H.; Yu, A. J. Phys. Chem. C 2014, 118, 11628.

(45) Stroyuk, A. L.; Panasiuk, Y. V.; Raevskaya, A. E.; Kuchmy, S. Y. Theor. Exp. Chem. 2015, 51, 243.

(46) Fan, X.; Xing, Z.; Shu, Z.; Zhang, L.; Wang, L.; Shi, J. RSC Adv. 2015, 5, 8323.

(47) Gan, Z.; Shan, Y.; Chen, J.; Gui, Q.; Zhang, Q.; Nie, S.; Wu, X. Nano Res. 2016, 9, 1801.

(48) Zhang, Y.; Pan, Q.; Chai, G.; Liang, M.; Dong, G.; Zhang, Q.; Qiu, J. Sci. Rep. 2013, 3, 1943.

(49) Xu, J.; Shalom, M.; Piersimoni, F.; Antonietti, M.; Neher, D.; Brenner, T. J. K. Adv. Opt. Mater. 2015, 3, 913.

(50) Knorr, F. J.; Mercado, C. C.; McHale, J. L. J. Phys. Chem. C 2008, 112, 12786 .

(51) Wilkinson, F. J. Chem. Soc., Faraday Trans. 2 1986, 82, 2073.

(52) Müller, J. G.; Lemmer, U.; Feldmann, J.; Scherf, U. Phys. Rev. Lett. 2002, 88, 147401.
(53) Müller, J. G.; Lupton, J. M.; Feldmann, J.; Lemmer, U.; Scharber, M. C.; Sariciftci, N. S.; Brabec, C. J.; Scherf, U. Phys. Rev. B: Condens. Matter Mater. Phys. 2005, 72, 195208.

(54) Nelson, J.; Chandler, R. E. Coord. Chem. Rev. 2004, 248, 1181.

(55) Yoshihara, T.; Katoh, R.; Furube, A.; Tamaki, Y.; Murai, M.; Hara, K.; Murata, S.; Arakawa, H.; Tachiya, M. J. Phys. Chem. B 2004, 108, 3817.

(56) Tamaki, Y.; Furube, A.; Murai, M.; Hara, K.; Katoh, R.; Tachiya, M. Phys. Chem. Chem. Phys. 2007, 9, 1453.

(57) Clarke, T. M.; Jamieson, F. C.; Durrant, J. R. J. Phys. Chem. C 2009, 113, 20934.

(58) Shiraishi, Y.; Kofuji, Y.; Kanazawa, S.; Sakamoto, H.; Ichikawa, S.; Tanaka, S.; Hirai, T. Chem. Commun. 2014, 50, 15255.

(59) Merschjann, C.; Tyborski, T.; Orthmann, S.; Yang, F.; Schwarzburg, K.; Lublow, M.; Lux-Steiner, M. C.; Schedel-Niedrig, T. Phys. Rev. B: Condens. Matter Mater. Phys. 2013, 87, 205204.

(60) Srimath Kandada, A. R.; Neutzner, S.; D'Innocenzo, V.; Tassone, F.; Gandini, M.; Akkerman, Q. A.; Prato, M.; Manna, L.; Petrozza, A.; Lanzani, G. J. Am. Chem. Soc. 2016, 138, 13604.

(61) Cowan, A. J.; Tang, J.; Leng, W.; Durrant, J. R.; Klug, D. R. J. Phys. Chem. C 2010, 114, 4208.

(62) Ma, Y.; Pendlebury, S. R.; Reynal, A.; Le Formal, F.; Durrant, J. R. Chem. Sci. 2014, 5, 2964.

(63) Pendlebury, S. R.; Barroso, M.; Cowan, A. J.; Sivula, K.; Tang, J.; Gratzel, M.; Klug, D.; Durrant, J. R. Chem. Commun. 2011, 47, 716.

(64) Nelson, J. Phys. Rev. B: Condens. Matter Mater. Phys. 2003, 67, 155209.

(65) Chihaya, A. Jpn. J. Appl. Phys. 2014, 53, 060101.

(66) Pendlebury, S. R.; Cowan, A. J.; Barroso, M.; Sivula, K.; Ye, J.; Gratzel, M.; Klug, D. R.; Tang, J.; Durrant, J. R. Energy Environ. Sci. 2012, 5, 6304.

(67) Pendlebury, S. R.; Wang, X.; Le Formal, F.; Cornuz, M.; Kafizas, A.; Tilley, S. D.; Grätzel, M.; Durrant, J. R. J. Am. Chem. Soc. 2014, $136,9854$.

(68) Schneider, J.; Matsuoka, M.; Takeuchi, M.; Zhang, J.; Horiuchi, Y.; Anpo, M.; Bahnemann, D. W. Chem. Rev. 2014, 114, 9919.

(69) Cherepy, N. J.; Liston, D. B.; Lovejoy, J. A.; Deng, H.; Zhang, J. Z. J. Phys. Chem. B 1998, 102, 770.

(70) Etzold, F.; Howard, I. A.; Mauer, R.; Meister, M.; Kim, T.-D.; Lee, K.-S.; Baek, N. S.; Laquai, F. J. Am. Chem. Soc. 2011, 133, 9469.

(71) Blom, P. W. M.; Mihailetchi, V. D.; Koster, L. J. A.; Markov, D. E. Adv. Mater. 2007, 19, 1551.

(72) Melissen, S.; Le Bahers, T.; Steinmann, S. N.; Sautet, P. J. Phys. Chem. C 2015, 119, 25188.

(73) Gioti, M.; Logothetidis, S. Diamond Relat. Mater. 2003, 12, 957.

(74) Lau, V. W.; Moudrakovski, I.; Botari, T.; Weinberger, S.; Mesch, M. B.; Duppel, V.; Senker, J.; Blum, V.; Lotsch, B. V. Nat. Commun. 2016, 7, 12165

(75) Cui, Y.; Ding, Z.; Liu, P.; Antonietti, M.; Fu, X.; Wang, X. Phys. Chem. Chem. Phys. 2012, 14, 1455.

(76) Hollmann, D.; Karnahl, M.; Tschierlei, S.; Kailasam, K.; Schneider, M.; Radnik, J.; Grabow, K.; Bentrup, U.; Junge, H.; Beller, M.; Lochbrunner, S.; Thomas, A.; Brückner, A. Chem. Mater. 2014, 26, 1727.

(77) Lau, V. W.-h.; Klose, D.; Kasap, H.; Podjaski, F.; Pignié, M.-C.; Reisner, E.; Jeschke, G.; Lotsch, B. V. Angew. Chem., Int. Ed. 2017, 56, 510.

(78) Butchosa, C.; Guiglion, P.; Zwijnenburg, M. A. J. Phys. Chem. C 2014, 118, 24833.

(79) Lau, V. W.-h.; Yu, V. W.-z.; Ehrat, F.; Botari, T.; Moudrakovski, I.; Simon, T.; Duppel, V.; Medina, E.; Stolarczyk, J.; Feldmann, J.; Blum, V.; Lotsch, B. V. Adv. Energy Mater. 2017, 1602251.

(80) Ran, J.; Ma, T. Y.; Gao, G.; Du, X.-W.; Qiao, S. Z. Energy Environ. Sci. 2015, 8, 3708.

(81) Chen, X.; Liu, L.; Yu, P. Y.; Mao, S. S. Science 2011, 331, 746.

(82) Liu, F.; Concepcion, J. J.; Jurss, J. W.; Cardolaccia, T.; Templeton, J. L.; Meyer, T. J. Inorg. Chem. 2008, 47, 1727. 